\title{
Kinetic Study on the Leaching of Pt, Pd and Rh from Automotive Catalyst Residue by Using Chloride Solutions
}

\author{
Yucai Cao ${ }^{1, * 1}$, Sri Harjanto ${ }^{2}$, Atsushi Shibayama ${ }^{1,3, * 2}$, Isao Naitoh ${ }^{4}$, Toshiyuki Nanami ${ }^{4}$, \\ Koichi Kasahara ${ }^{4}$, Yoshiharu Okumura ${ }^{5}$ and Toyohisa Fujita ${ }^{6}$ \\ ${ }^{1}$ Venture Business Laboratory, Akita University, Akita 010-8502, Japan \\ ${ }^{2}$ Department of Metallurgical and Materials Engineer, University of Indonesia, Kampus Baru UI, Depok 16424, Indonesia \\ ${ }^{3}$ Department of Material Process Engineering and Applied Chemistry for Environment, Faculty of Engineering and Resource Science, \\ Akita University, Akita 010-8502, Japan \\ ${ }^{4}$ Cataler, Co., Ogasa-Gun 437-1492, Japan \\ ${ }^{5}$ Knowledgenet, Co., Tokyo 135-8073, Japan \\ ${ }^{6}$ Department of Geosystem Engineering, Graduate School of Engineering, The University of Tokyo, Tokyo 113-8656, Japan
}

Recycling platinum group metals (PGMs) from waste and/or secondary resources is becoming quite important due to the limitation of the natural resource deposits of PGMs. Among the processes of PGMs' recycling from secondary resources, the hydrometallurgical method draws extensive concerns, particularly for the selection of leaching solution. The present work evaluated the ability of chloride leaching solutions, i.e. $\mathrm{HCl}-\mathrm{H}_{2} \mathrm{O}_{2}$ and $\mathrm{NaClO}-\mathrm{HCl}-\mathrm{H}_{2} \mathrm{O}_{2}$ to extract $\mathrm{Pt}$, $\mathrm{Pd}$ and $\mathrm{Rh}$ from a kinetic point of view. The effect of temperature in the range of $277-307 \mathrm{~K}$ and time were also examined under the conditions of $-500 \mu \mathrm{m}$ of particle size and $100 \mathrm{~g} \mathrm{~L}^{-1}$ of pulp density.

$$
\text { The kinetic model }(\mathrm{I}): \quad\left((1-\alpha)^{-1 / 3}-1\right)+\frac{1}{3} \ln (1-\alpha)=k_{1} t
$$

was found to be the most suitable to describe the leaching process of $\mathrm{Pt}, \mathrm{Pd}$ and $\mathrm{Rh}$ in the $\mathrm{NaClO}$ contained solution. In this model the interface transfer and diffusion across the leached support layer both affect the rate of leaching reaction.

$$
\text { Model (II): } \quad\left(1-(1-\alpha)^{1 / 3}\right)^{2}=k_{2} \ln (t)
$$

fits the kinetic data very well for the dissolution of $\mathrm{Pd}$ in the $\mathrm{HCl}-\mathrm{H}_{2} \mathrm{O}_{2}$ solution, showing that the diffusion across the leached support layer mainly affect the kinetic behaviors and the diffusion coefficient is inversely proportional to leaching time $t$.

The $\mathrm{NaClO}$ contained solution and $\mathrm{HCl}-\mathrm{H}_{2} \mathrm{O}_{2}$ solution leaching of $\mathrm{Pt}, \mathrm{Pd}$ and $\mathrm{Rh}$ are strongly dependent on the leaching temperature. In the case of the $\mathrm{NaClO}$ contained solution, the activation energy based on model (I) for Pd, Pt and $\mathrm{Rh}$ was $63.5,59.1$ and $77.9 \mathrm{~kJ}^{\mathrm{mol}}{ }^{-1}$, respectively. It is probably because of that the diffusion of $\mathrm{NaClO}$ contained solution across the leached support layer was very slow due to the micro-porous structure of the catalyst; and a high activation energy was needed in effect. Regarding to the leaching in the $\mathrm{HCl}-\mathrm{H}_{2} \mathrm{O}_{2}$ solution, the activation energy for Pd was $13.4 \mathrm{~kJ} \mathrm{~mol}^{-1}$ on the basis of model (II). [doi:10.2320/matertrans.47.2015]

(Received September 12, 2005; Accepted May 15, 2006; Published August 15, 2006)

Keywords: PGMs, natrium hypochlorite, recycling, kinetics, support layer, diffusion-controlled, one-step leaching

\section{Introduction}

Recently, the limited natural resource of precious metals arouses people to make efforts to recycle them from the waste as a secondary resource. Spent automotive catalyst and/or catalyst residue containing PGMs (Platinum Group Metals) are potential secondary resources of platinum $(\mathrm{Pt})$, palladium (Pd) and rhodium (Rh). Therefore, many studies were conducted to maximize the recovery of PGMs from the spent automotive catalyst and catalyst residue.

There are several processes to recycle PGMs from the spent automotive catalyst. Generally, hydrometallurgical process is one of the most employed, including a leaching step. In this process, aqua regia and mineral acids, such as hydrochloric acid, nitric acid and sulfuric acid were usually utilized to dissolve PGMs. Many works have been carried out to obtain a maximum recovery of PGMs with various conditions of leaching. ${ }^{1-5)}$

In the previous report, ${ }^{6}$ ) the leaching of $\mathrm{Pt}, \mathrm{Pd}$ and $\mathrm{Rh}$ was undertaken in $\mathrm{NaClO}-\mathrm{HCl}-\mathrm{H}_{2} \mathrm{O}_{2}$ and $\mathrm{HCl}-\mathrm{H}_{2} \mathrm{O}_{2}$ solutions.

\footnotetext{
${ }^{* 1}$ Present address: Organic Chemistry Division, Shanghai Research Institute of Chemical Industry (China).

${ }^{* 2}$ Corresponding author, E-mail: sibayama@ipc.akita-u.ac.jp
}

The recovery of PGMs has an order from the highest of Pd, Pt and $\mathrm{Rh}$. However, the results are still not enough to provide a satisfied explanation for the reaction mechanism in terms of the leaching of PGMs from the automotive catalyst residue. Based on the thermodynamic data, the formation potential of chloro-complex follows the order below:

$$
\begin{array}{ll}
\mathrm{Pt}+6 \mathrm{Cl}^{-}=\mathrm{PtCl}_{6}{ }^{2-}+4 \mathrm{e}^{-} & \mathrm{E}^{\mathrm{o}}=-0.744 \mathrm{~V} \\
\mathrm{Pd}+4 \mathrm{Cl}^{-}=\mathrm{PdCl}_{4}{ }^{2-}+2 \mathrm{e}^{-} & \mathrm{E}^{\mathrm{o}}=-0.620 \mathrm{~V} \\
\mathrm{Rh}+6 \mathrm{Cl}^{-}=\mathrm{RhCl}_{6}{ }^{3-}+3 \mathrm{e}^{-} & \mathrm{E}^{\mathrm{o}}=-0.450 \mathrm{~V}
\end{array}
$$

The leaching of $\mathrm{Rh}$ was found to be somewhat difficult among the three metals. ${ }^{6)}$ It is necessary to confirm whether there are any difference in the leaching kinetics of PGMs, because the kinetics is also one of the most important aspects for a leaching reaction.

A kinetic study on the leaching of gold $(\mathrm{Au})$, one of the precious metals, using reagents such as aqua regia and mineral acids, was conducted. ${ }^{7}$ ) Another kinetic study on the cyanidation of gold ore was also carried out. ${ }^{8)}$ However, the kinetic data and model analysis were not available for the other precious metals. Those works will not be reviewed further in this part because of the difference of the leaching system. The kinetic study on the leaching of PGMs from the automotive catalyst residue is very limited. In fact, the 


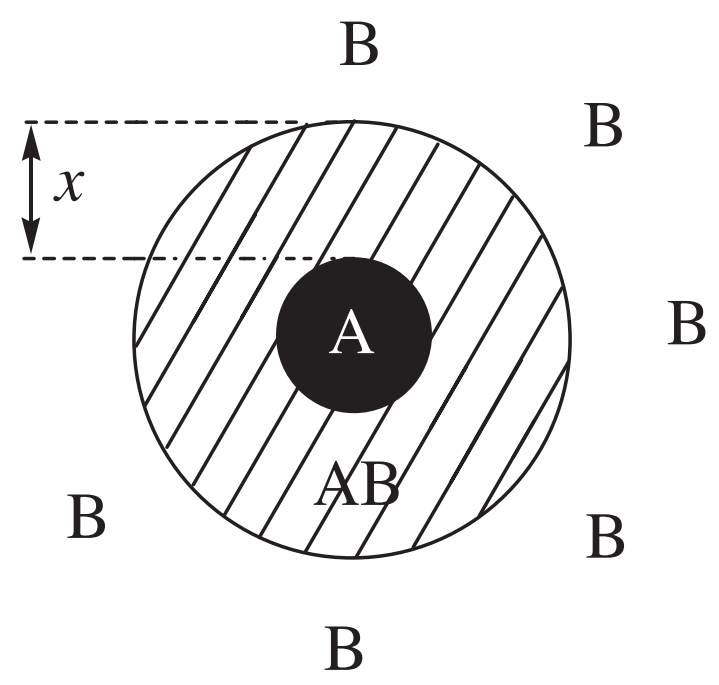

Fig. 1 Schematic representation of solid-liquid reaction model for the leaching of catalyst residues (PGMs contained catalyst A, Leaching active components $\mathrm{B}$ and leached support layer $\mathrm{AB}$ ).

automotive catalyst was composed of supported PGMs as active components and support material being of microporous structure and high surface area. Whether or not the structure of the catalyst residue will affect the leaching behavior of PGMs is still left as a question. Accordingly, the leaching kinetics of PGMs from the automotive catalyst residue is fairly important and necessary to be elucidated. The present study aims to study the kinetic of the reaction by comparing the kinetic parameters, leaching rate and activation energy to understand the possible mechanism occurred during the leaching of PGMs from automobile catalyst residue. The leaching solution containing chloride based leaching reagents i.e. $\mathrm{NaClO}-\mathrm{HCl}-\mathrm{H}_{2} \mathrm{O}_{2}$ and $\mathrm{HCl}-\mathrm{H}_{2} \mathrm{O}_{2}$ was employed.

\section{Kinetic Model}

In the present work, we assume the automotive catalyst residue is of uniform radii being spherical with homogenous structure and dispersion of PGMs, and is surrounded by the leaching active components as illustrated schematically in Fig. 1. In the diffusion controlled process the active components (noted as $\mathrm{B}$ in Fig. 1) e.g. $\mathrm{HCl}$ and $\mathrm{NaClO}$ must penetrate through the layer of the micro-porous support material being leached (noted as $\mathrm{AB}$ ) before reacting with the PGMs (noted as A) supported on the internal surface of the un-reacted core of catalyst. In the case of traditional derivation of kinetic model, a product layer was formed. However, in this case the products will dissolved in the solution instead of forming product layer. Using different assumptions for the leaching processes it is possible to derive kinetic equations that could be tested against the experimental data for a better fit. The assumptions and the derivation for the equations are set out below, starting from the first principles.

Referring to Fig. 1, let the original radius of the catalyst be $r_{0}$. At time $t$ the interface has spread inwards a distance $x$, leaving sphere of un-reacted catalyst A of radius $r$ :

$$
r=r_{0}-x
$$

Volume of the original sphere: $\frac{4}{3} \pi\left(r_{0}\right)^{3}$

Volume of sphere at time $t: \frac{4}{3} \pi\left(r_{0}-x\right)^{3}$

Value of fraction un-reacted is: $(1-\alpha)=\frac{\left(r_{0}-x\right)^{3}}{\left(r_{0}\right)^{3}}$

$$
\begin{aligned}
& \therefore(1-\alpha)^{1 / 3}=\frac{\left(r_{0}-x\right)}{\left(r_{0}\right)}=1-\frac{x}{r_{0}} \\
& \therefore x=r_{0}\left(1-(1-\alpha)^{1 / 3}\right) \\
& \frac{\mathrm{d} x}{\mathrm{~d} \alpha}=\frac{1}{3} r_{0}(1-\alpha)^{-2 / 3}
\end{aligned}
$$

If the model is a diffusion-controlled mechanism, a number of possible assumptions can be made to derive rate equations. The time dependence of the gradual upbuild of the leached layer of the porous support material can be described by the parabolic law. Rate varies inversely with $x$.

$$
\begin{aligned}
& x^{2}=2 D_{\mathrm{e}} V_{m} C_{0} t \\
& \therefore \frac{\mathrm{d} x}{\mathrm{~d} t}=\frac{D_{\mathrm{e}} V_{m} C_{0}}{x}
\end{aligned}
$$

where $x$ is the thickness of the leached layer, $D_{\mathrm{e}}$ is the diffusion coefficient (slowest transport), $V_{m}$ is the volume of the leached layer formed from $1 \mathrm{~mol}$ of the slowest penetrating component, and $C_{0}$ is the concentration of the penetrating species at the surface of the catalyst.

If the interface transfer and diffusion across the leached support layer both affect the rate, Equation (4) can evolved further:

$$
\frac{\mathrm{d} x}{\mathrm{~d} t}=\frac{D_{\mathrm{e}} V_{m} C_{0}}{x} \cdot 4 \pi r^{2}=\frac{k_{1} r^{2}}{x}
$$

where $k_{1}=4 \pi D_{\mathrm{e}} V_{m} C_{0}$.

Substitute for $x, \mathrm{~d} x$ and $r^{2}$ using eqs. (1), (2) and (3):

$$
\left(1-(1-\alpha)^{1 / 3}\right)(1-\alpha)^{-4 / 3} \mathrm{~d} \alpha=3 k_{1} \mathrm{~d} t
$$

Integrate and use boundary condition, $t=0$ and $\alpha=0$ :

$$
\left((1-\alpha)^{-1 / 3}-1\right)+\frac{1}{3} \ln (1-\alpha)=k_{1} t
$$

If the diffusion equation is

$$
\frac{\mathrm{d} x}{\mathrm{~d} t}=\frac{V_{m} C_{0}}{x} \cdot \frac{a}{t}
$$

where $D_{\mathrm{e}}$ was replaced by $a / t$, and $a$ is a constant. It means that the diffusion constant is inversely proportional to the reaction time. Integrate back:

$$
\begin{aligned}
& x^{2}=2 D_{\mathrm{e}} V_{m} C_{0} a \ln t \\
& \therefore r_{0}^{2}\left(1-(1-\alpha)^{1 / 3}\right)^{2}=2 D_{\mathrm{e}} V_{m} C_{0} a \ln t \\
& \text { or }\left(1-(1-\alpha)^{1 / 3}\right)^{2}=k_{2} \ln t
\end{aligned}
$$

where $k_{2}=2 D_{\mathrm{e}} V_{m} C_{0} a$.

With different assumptions other equations can also be derived based on eq. (4). A literature search for the kinetic equations and new equation derivation by Dickinson et al. ${ }^{9)}$ have identified 29 equations in total and 12 of these are based on the diffusion-controlled mechanism. In addition, three 
Table 1 The kinetic equations based on diffusion controlled mechanism. ${ }^{9)}$

\begin{tabular}{|c|c|c|}
\hline Equation & Type & Notation \\
\hline$k t=\alpha^{2}$ & One-dimensional & D1 \\
\hline$k t=(1-\alpha) \ln (1-\alpha)+\alpha$ & Two-dimensional & D2 \\
\hline$k t=\left(1-(1-\alpha)^{1 / 3}\right)^{2}$ & Jander (three-dimensional) & D3 \\
\hline$k t=1-2 \alpha / 3-(1-\alpha)^{2 / 3}$ & Ginstling-Brounshtein & D4 \\
\hline$k t=\left(1 /(1-\alpha)^{1 / 3}-1\right)^{2}$ & Zhuravlev, Lesokhin and Templeman & D5 \\
\hline$k t=\left((1+\alpha)^{1 / 3}-1\right)^{2}$ & Anti-Jander (three-dimensional) & D6 \\
\hline$k t=\left(1-(1-\alpha)^{1 / 2}\right)^{2}$ & Jander (cylindrical diffusion) & D8 \\
\hline$k t=\left(1-(1+\alpha)^{1 / 3}\right)^{2}$ & Anti-Jander (cylindrical diffusion) & D9 \\
\hline$k t=1 /(1-\alpha)^{1 / 3}-1$ & New equation by Dickinson et al. ${ }^{9)}$ & D10 \\
\hline$k t=1 /(1-\alpha)^{1 / 3}+1 / 3 \ln (1-\alpha)-1$ & New equation by Dickinson et al. ${ }^{9)}$ & D11 \\
\hline$k t=1 / 5(1-\alpha)^{-5 / 3}-1 / 4(1-\alpha)^{-4 / 3}+1 / 20$ & New equation by Dickinson et al. ${ }^{9)}$ & D12 \\
\hline
\end{tabular}

Table 2 The kinetic equations for liquid-solid reaction. ${ }^{9)}$

\begin{tabular}{|c|c|c|}
\hline Equation & Type & Notation \\
\hline$k t=[-\ln (1-\alpha)]^{1 / 4}$ & Avrami-Erofeev & A1 \\
\hline$k t=[-\ln (1-\alpha)]^{1 / 2}$ & Avrami-Erofeev & A2 \\
\hline$k t=[-\ln (1-\alpha)]^{1 / 3}$ & Avrami-Erofeev & A3 \\
\hline$k t=[-\ln (1-\alpha)]^{3 / 4}$ & Avrami-Erofeev & A4 \\
\hline$k t=[-\ln (1-\alpha)]^{2 / 5}$ & Avrami-Erofeev & A5 \\
\hline$k t=\alpha$ & Zero order & F0 \\
\hline$k t=-\ln (1-\alpha)$ & First order & $\mathrm{F} 1$ \\
\hline$k t=(1-\alpha)^{-1}$ & Second order & $\mathrm{F} 2$ \\
\hline$k t=1-(1-\alpha)^{1 / 2}$ & $\begin{array}{l}\text { Interface } \\
\quad(\text { contracting area) }\end{array}$ & $\mathrm{R} 2$ \\
\hline$k t=1-(1-\alpha)^{1 / 3}$ & $\begin{array}{l}\text { Interface } \\
\quad \text { (contracting volume) }\end{array}$ & R3 \\
\hline$k t=1-(1-\alpha)^{2 / 3}$ & Interface & $\mathrm{R} 4$ \\
\hline$k t=\alpha^{1 / 2}$ & Power law (half) & $\mathrm{Pl}(n=2)$ \\
\hline$k t=\alpha^{1 / 3}$ & Power law (third) & $\mathrm{Pl}(n=3)$ \\
\hline$k t=\alpha^{1 / 4}$ & Power law (quarter) & $\mathrm{Pl}(n=4)$ \\
\hline$k t=\ln \alpha$ & Exponential & E1 \\
\hline$k t=\exp (-(1-\alpha))-\exp (-1)$ & Exponential & E2 \\
\hline$k t=\ln (\alpha /(1-\alpha))$ & Prout-Tompkinsa & B1 \\
\hline
\end{tabular}

new equations were deduced on the basis of diffusioncontrolled mechanism. Table 1 lists the diffusion-controlled equations and Table 2 lists the other 17 equations. The notation used in the tables was listed according to literature.

Rate constant $\left(k, \mathrm{~s}^{-1}\right)$, considered as a function of reaction temperature, can be formulated by the following equation, known as Arrhenius equation:

$$
k=A e^{-E_{a} / R T}
$$

where $E_{a}$ is the apparent activation energy $\left(\mathrm{kJ} \mathrm{mol}^{-1}\right) ; R$ is the ideal gas constant, $8.314 \times 10^{-3}\left(\mathrm{~J} \mathrm{~mol}^{-1} \mathrm{~K}^{-1}\right) ; T$ is the reaction temperature $(\mathrm{K})$; and $A$ is the pre-exponential factor $\left(\mathrm{s}^{-1}\right)$.

\section{Experimental Method}

The automotive catalyst residue containing PGMs i.e. the residue of the automotive catalyst rejected from the manufacturing process was supplied by Cataler Co. Additional processes such as pelletizing and reduction by using hydro-
Table 3 Composition of PGM analyzed by ICP (wet-analysis) after alkali leaching.

\begin{tabular}{cc}
\hline Elements & {$[\mathrm{PR}]($ mass \%) } \\
\hline $\mathrm{Pt}$ & 0.379 \\
$\mathrm{Pd}$ & 0.582 \\
$\mathrm{Rh}$ & 0.239 \\
\hline
\end{tabular}

gen gas were also conducted to the sample in the company. In the present experiments the received sample was ground and sieved to powder with a size of less than $500 \mu \mathrm{m}(-500 \mu \mathrm{m})$. The powder sample was kept in a desiccator to avoid contamination. The PGMs' compositions of the powder are listed in Table 3. The sample also contained more than 90 mass\% of support materials such as $\mathrm{Al}_{2} \mathrm{O}_{3}$ and silicate and doped components e.g. $\mathrm{CeO}_{2}, \mathrm{ZrO}_{2}, \mathrm{BaO}$ and other oxides. The reagents used in the experiments were $\mathrm{NaClO}$ solution (8.5-13.5\% active chlorine, Nacalai tesque), $\mathrm{HCl}(35-37 \%=$ $12 \mathrm{M}$, Nacalai tesque) and $\mathrm{H}_{2} \mathrm{O}_{2}(30 \%$, Nacalai tesque). Bidistilled water was used for rinsing, washing and dilluting the solution in all the experiments. Two kinds of leaching solution were prepared, i.e., $\mathrm{NaClO}$ (3 vol\%)- $\mathrm{HCl}(5 \mathrm{M})-$ $\mathrm{H}_{2} \mathrm{O}_{2}(1 \mathrm{vol} \%)$ noted as $\mathrm{NaClO}$ contained solution and $\mathrm{HCl}$ $(11.6 \mathrm{M})-\mathrm{H}_{2} \mathrm{O}_{2}(1 \mathrm{vol} \%)$ noted as $\mathrm{HCl}-\mathrm{H}_{2} \mathrm{O}_{2}$ solution.

A glass beaker filled with a leaching solution was put into the water bath and being controlled to the working temperature within a limited error level. For the effective controlling of temperature and convenience of sampling, the temperatures of the kinetic experiment was lower than that for the application of leaching process to obtain observable data of the reaction. The leaching temperature was isothermally set at 277,297 and $307 \mathrm{~K}$. For low temperature $(277 \mathrm{~K})$, ice water was utilized to cool the glass beaker. To eliminate the increasing of temperature due to the heat released from the reaction and to keep the experiment under the isothermal condition, cooling water in the bath was flowed continuously during the leaching at temperature 297 and $307 \mathrm{~K}$. The pulp density for the leaching was set at $100 \mathrm{~g} \mathrm{~L}^{-1}$ (20 g sample in $200 \mathrm{~mL}$ solution). Twenty grams of the sample powder was added at once into the agitated leaching solution in the 500 $\mathrm{mL}$ glass beaker at the required temperature. The magnetic stirrer rotation was kept constant at $600 \mathrm{rpm}$. At a certain time interval, 1-mL leaching solution sample was taken by using a 

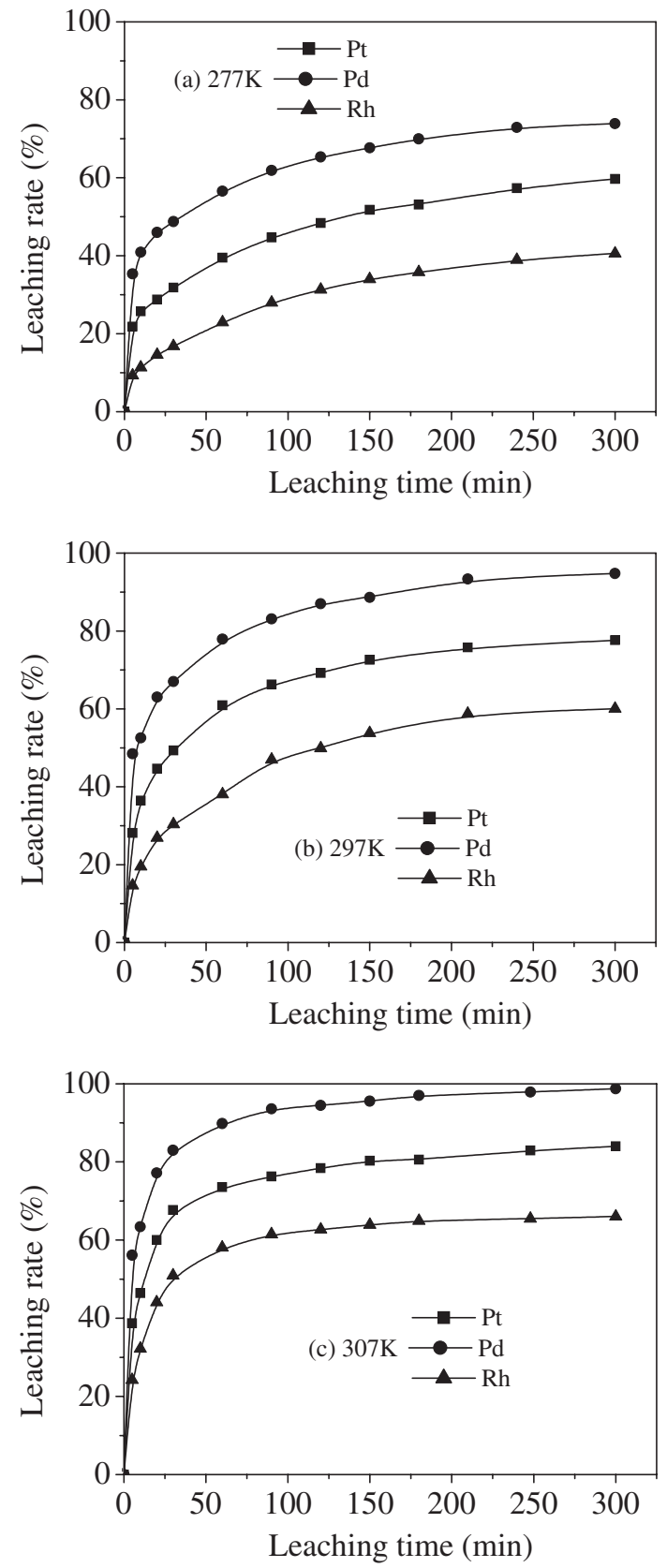

Fig. 2 Effect of leaching time and temperature on the dissolution of $\mathrm{Pd}$, Pt and $\mathrm{Rh}$ in $\mathrm{NaClO}$ based leaching solution: (a) $277 \mathrm{~K}$; (b) $297 \mathrm{~K}$ and (c) $307 \mathrm{~K}$.

syringe filter of $0.45 \mu \mathrm{m}$ pore size. Rinsing of syringe was undertaken with $3 \mathrm{~mL}$ bi-distilled water. Since the solid and liquid mixture was in the homogenous suspension form, the solid-liquid ratio (pulp density) was maintained constant $\left(100 \mathrm{~g} \mathrm{~L}^{-1}\right)$. The total volume of sampling solution removed from the glass beaker was about $6 \%$ of the original, and did not show apparent effect on the kinetic measurement.

The solution samples were diluted with bi-distilled water and then analyzed by using induction coupling plasma spectrophotometer (ICP, Seiko Instrument, Inc.). In order to decrease the deviation of the kinetic analysis, for each case of leaching the utmost of the leaching rate was extrapolated according to the time-on-stream behavior, and then was used as the base to calculate dissolution fraction $\alpha$.
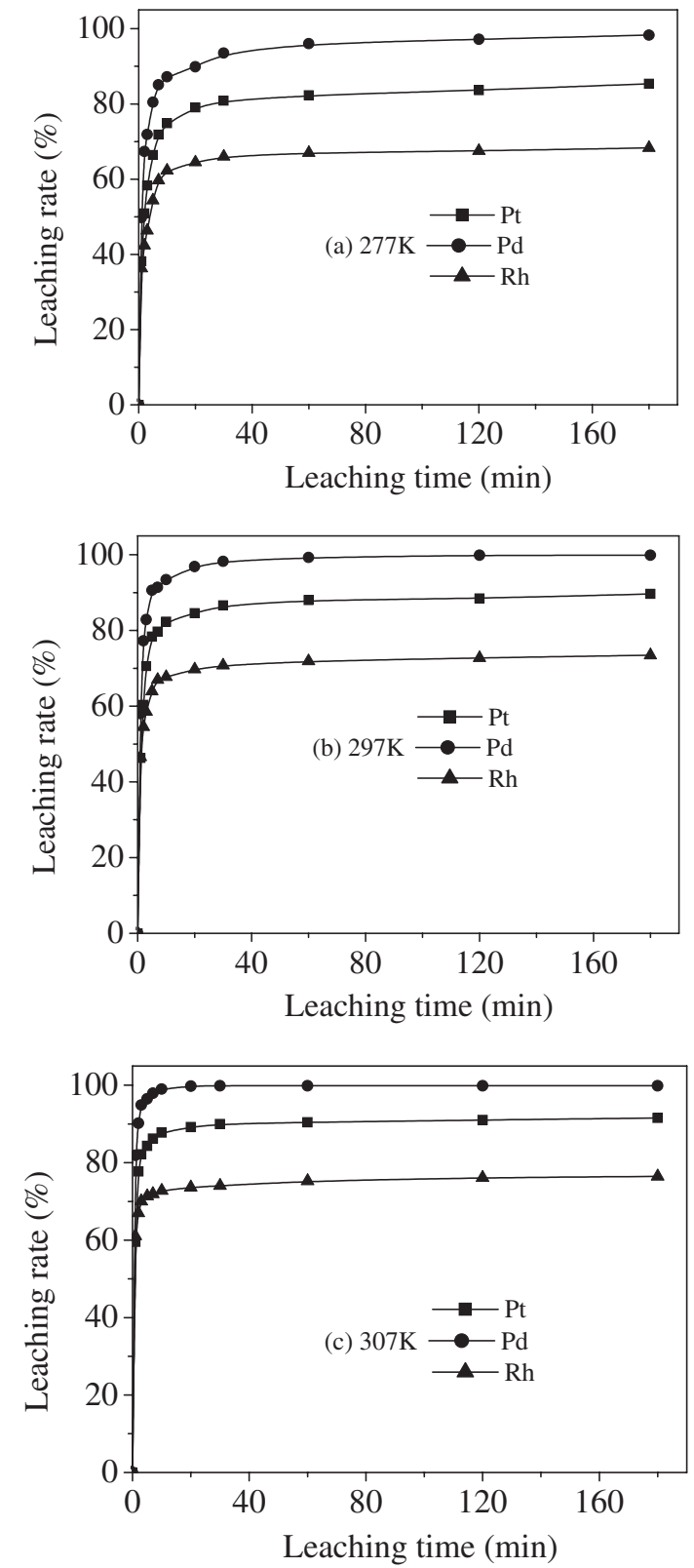

Fig. 3 Effect of leaching time and temperature on the dissolution of $\mathrm{Pd}$, $\mathrm{Pt}$ and $\mathrm{Rh}$ in $\mathrm{HCl}-\mathrm{H}_{2} \mathrm{O}_{2}$ based leaching solution: (a) $277 \mathrm{~K}$; (b) $297 \mathrm{~K}$ and (c) $307 \mathrm{~K}$.

\section{Results and Discussion}

\subsection{Results}

The effect of leaching time and temperature on the dissolution of $\mathrm{Pt}, \mathrm{Pd}$ and $\mathrm{Rh}$ in the $\mathrm{NaClO}$ contained leaching solution was shown in Fig. 2 (a) $277 \mathrm{~K}$; (b) $297 \mathrm{~K}$ and (c) $307 \mathrm{~K}$, and the leaching behaviors in the $\mathrm{HCl}-\mathrm{H}_{2} \mathrm{O}_{2}$ solution were shown in Fig. 3 (a) $277 \mathrm{~K}$; (b) $297 \mathrm{~K}$ and (c) $307 \mathrm{~K}$. The results in Figs. 2 and 3 showed that the dissolution of each PGMs increases with increasing leaching temperature and time on stream for both solutions. The dissolution of Pt, Pd and $\mathrm{Rh}$ in the $\mathrm{HCl}-\mathrm{H}_{2} \mathrm{O}_{2}$ solution was relatively faster as compared with that of the $\mathrm{NaClO}$ contained solution. For instance, it takes more than 100 minutes to maximize the dissolution of $\mathrm{Pd}(>95 \%)$ at $307 \mathrm{~K}$ for the $\mathrm{NaClO}$ contained solution, whilst for the $\mathrm{HCl}-\mathrm{H}_{2} \mathrm{O}_{2}$ solution it only takes about 

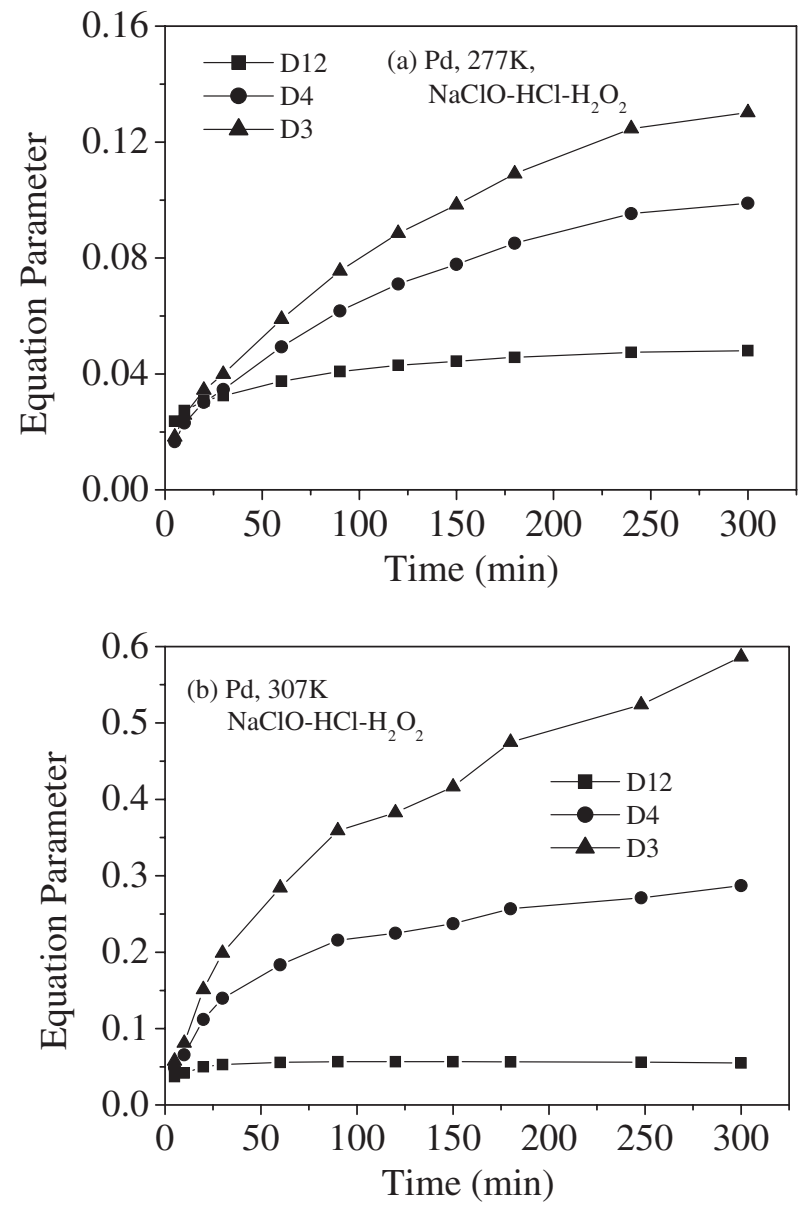

Fig. 4 Plot of kinetic equation parameter (D12, D4 and D3, see Table 1) versus leaching time for the leaching of $\mathrm{Pd}$ in $\mathrm{NaClO}$ contained leaching solution at $277 \mathrm{~K}$ (a) and $307 \mathrm{~K}(\mathrm{~b})$.

several minutes to get a maximum dissolution of $\mathrm{Pd}(>95 \%)$ at the same temperature, meaning that the $\mathrm{HCl}-\mathrm{H}_{2} \mathrm{O}_{2}$ solution is more active than the $\mathrm{NaClO}$ contained solution to dissolve PGMs. In fact, the $\mathrm{HCl}$ concentration of the $\mathrm{HCl}-$ $\mathrm{H}_{2} \mathrm{O}_{2}$ solution is remarkably higher than that of the $\mathrm{NaClO}$ contained solution $\left(11.6 \mathrm{~mol} \mathrm{~L}^{-1}\right.$ vs $\left.5.0 \mathrm{~mol} \mathrm{~L}^{-1}\right)$. If we employ solutions with the same $\mathrm{HCl}$ concentration of $5 \mathrm{~mol} \mathrm{~L}^{-1}$ to dissolve PGMs, the leaching rate of PGMs will be lower in the solution without the addition of $\mathrm{NaClO}$, manifesting a significant promoting effect of $\mathrm{NaClO} .{ }^{6}$ For both solutions, the dissolution of PGMs follows the order of $\mathrm{Pd}, \mathrm{Pt}$ and $\mathrm{Rh}$ from the highest.

\subsection{Data analysis}

The authors attempted to use the equations listed in Tables 1 and 2 to analyze the kinetic data. The initial kinetic analysis did not give a perfect fit to the equations in Table 2. This suggests that the leaching of PGMs from automotive catalyst residue under the present experimental conditions was not a reaction-controlled process. On the contrary, the diffusion-controlled mechanism seems to be dominant in this case. It was decided, therefore, to analyze the isothermal data again by using the equations in Table 1 based on diffusioncontrolled reaction model.

Figure 4 showed the kinetic plot between the equation

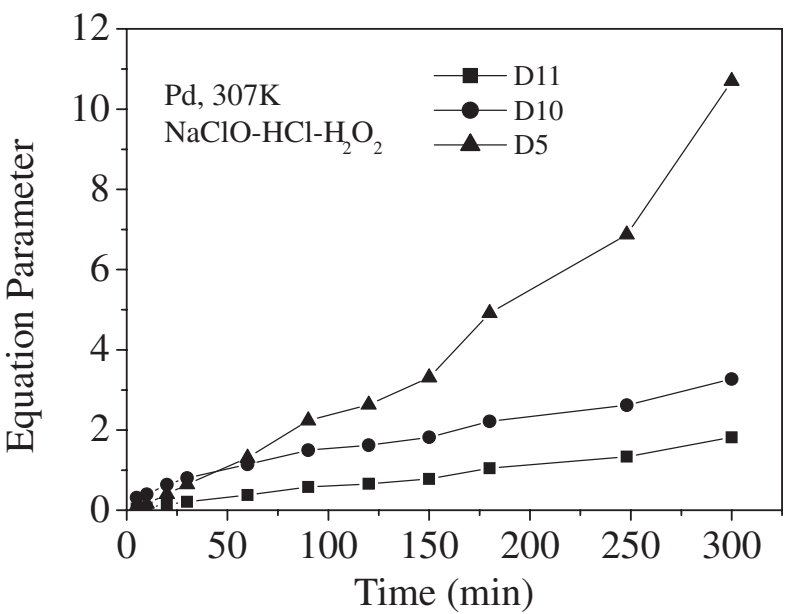

Fig. 5 Plot of kinetic equation parameter (D11, D10 and D5, see Table 1) versus leaching time for the leaching of $\mathrm{Pd}$ in $\mathrm{NaClO}$ contained leaching solution at $307 \mathrm{~K}$.

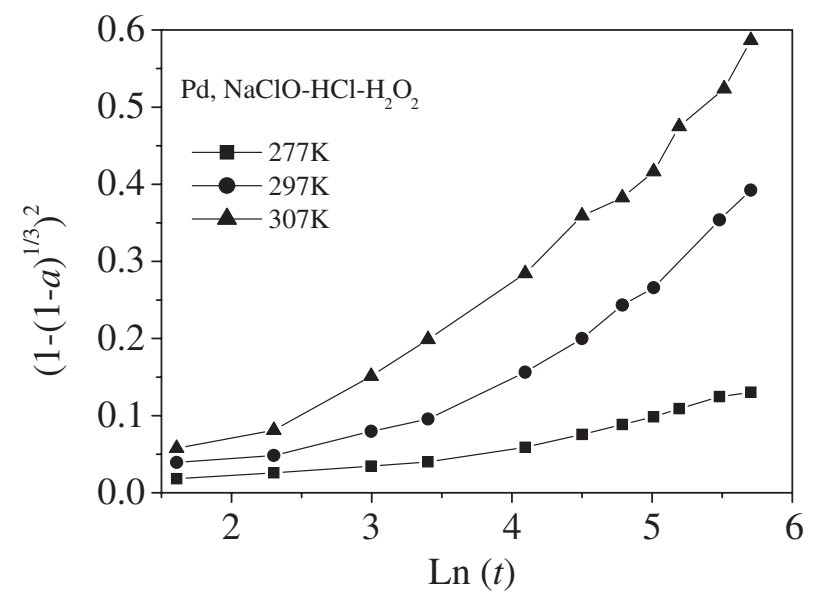

Fig. 6 Plot of kinetic equation parameter (D7, see Table 1) versus $\ln t$ for the leaching of $\mathrm{Pd}$ in $\mathrm{NaClO}$ contained leaching solution: Effect of temperature.

parameter (D12, D4 and D3) and time on stream for the leaching of $\mathrm{Pd}$ in the $\mathrm{NaClO}$ contained solution at $277 \mathrm{~K}$ (a) and 307 (b), respectively. A good linear relationship cannot be found. The data analysis with regard to the kinetic behavior of the Pd leaching in the same solution at $307 \mathrm{~K}$ was shown in Fig. 5 by using kinetic eq. D5, D10 and D11 (Table 1). eq. D11 can well fit the kinetic data and with an intercept near to zero, although for D5 and D10 such kind of behavior cannot be found. In addition, the diffusion-controlled equation D7 cannot well fit the kinetic data for the leaching of $\mathrm{Pd}$ in the $\mathrm{NaClO}$ contained solution (Fig. 6).

Regarding to the leaching of $\mathrm{Pd}$ in the $\mathrm{HCl}-\mathrm{H}_{2} \mathrm{O}_{2}$ solution system, similar behavior can be found (Fig. 7). Among these equations, model D11 showed a good linear relation and an intercept near to zero. Whether or not the kinetic equation D11 can describe the leaching behavior of $\mathrm{Pt}$ and $\mathrm{Rh}$ also, we will analyze the kinetic data further using equation D11.

For the leaching of Pd (a), Pt (b) and Rh (c) in the $\mathrm{NaClO}$ contained leaching solution, Figure 8 plotted the parameter $\left(1 /(1-\alpha)^{1 / 3}-1\right)+1 / 3 \ln (1-\alpha) \quad($ see D11 in Table 1$)$ 

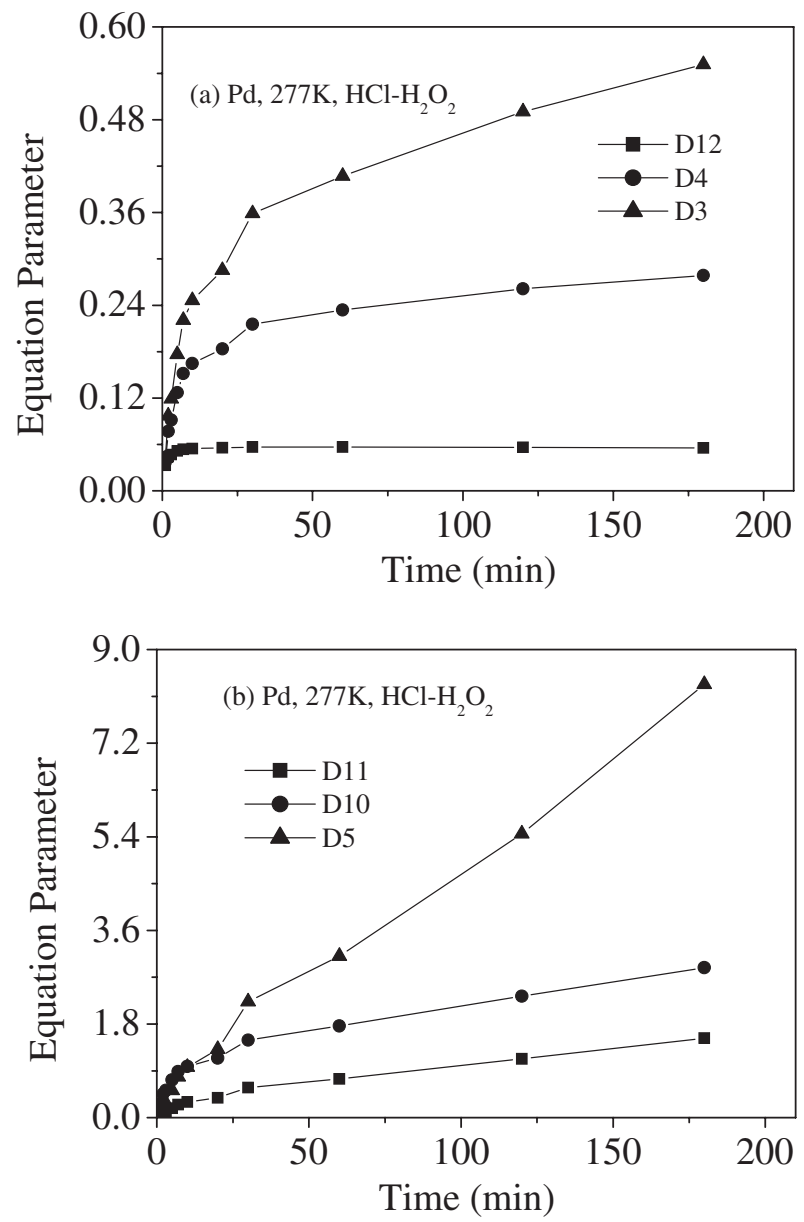

Fig. 7 Plot of kinetic equation parameter versus leaching time for the leaching of $\mathrm{Pd}$ in $\mathrm{HCl}-\mathrm{H}_{2} \mathrm{O}_{2}$ leaching solution at $277 \mathrm{~K}$ : (a) D12, D4 and D3; (b) D11, D10 and D5 (see Table 1).

versus the leaching time with different temperature. Indeed, eq. D11 fits the kinetic data well, showing a good linear relationship for the total leaching period studied. The correlations for each line were calculated with values from 0.983 to 0.998 .

Figure 9 shows the plot of parameter $\left(1 /(1-\alpha)^{1 / 3}-1\right)+$ $1 / 3 \ln (1-\alpha)$ versus leaching time in terms of the leaching of $\mathrm{Pd}$ (a), $\mathrm{Pt}$ (b) and $\mathrm{Rh}$ (c) in $\mathrm{HCl}-\mathrm{H}_{2} \mathrm{O}_{2}$ based leaching solution. During the temperature range of $277 \mathrm{~K}-307 \mathrm{~K}$, eq. D11 can describe the leaching process of Pd (Fig. 9(a)), particularly for the beginning of the dissolution (0-10 min), showing correlations $>0.97$. Figure 10 plots $(1-(1-$ $\left.\alpha)^{1 / 3}\right)^{2}$ versus $\ln t$ for the leaching of $\mathrm{Pd}(\mathrm{a}), \mathrm{Pt}(\mathrm{b})$ and $\mathrm{Rh}$ (c) in the $\mathrm{HCl}-\mathrm{H}_{2} \mathrm{O}_{2}$ solution. Good linear correlation can be found for the leaching of $\mathrm{Pd}$ with $\mathrm{R}>0.99$. However, in the case of Pt (Figs. 9(b) and 9(c)), Rh (Figs. 10(b) and 10(c)), the plot severely deviated from linear correlation, meaning that in the $\mathrm{HCl}-\mathrm{H}_{2} \mathrm{O}_{2}$ solution the leaching kinetics of $\mathrm{Pt}$ and $\mathrm{Rh}$ was far different from that as in the case of Pd. All the 29 equations were questionable for the leaching of $\mathrm{Pt}$ and $\mathrm{Rh}$ by using $\mathrm{HCl}-\mathrm{H}_{2} \mathrm{O}_{2}$ solution with high concentration of $\mathrm{HCl}$, because of the big discrepancies, and it is believed that they are not suitable models, although D11 was proven to be perfect to fit the kinetic data in the case of $\mathrm{NaClO}$ contained solution. A more suitable kinetic equation is absolutely
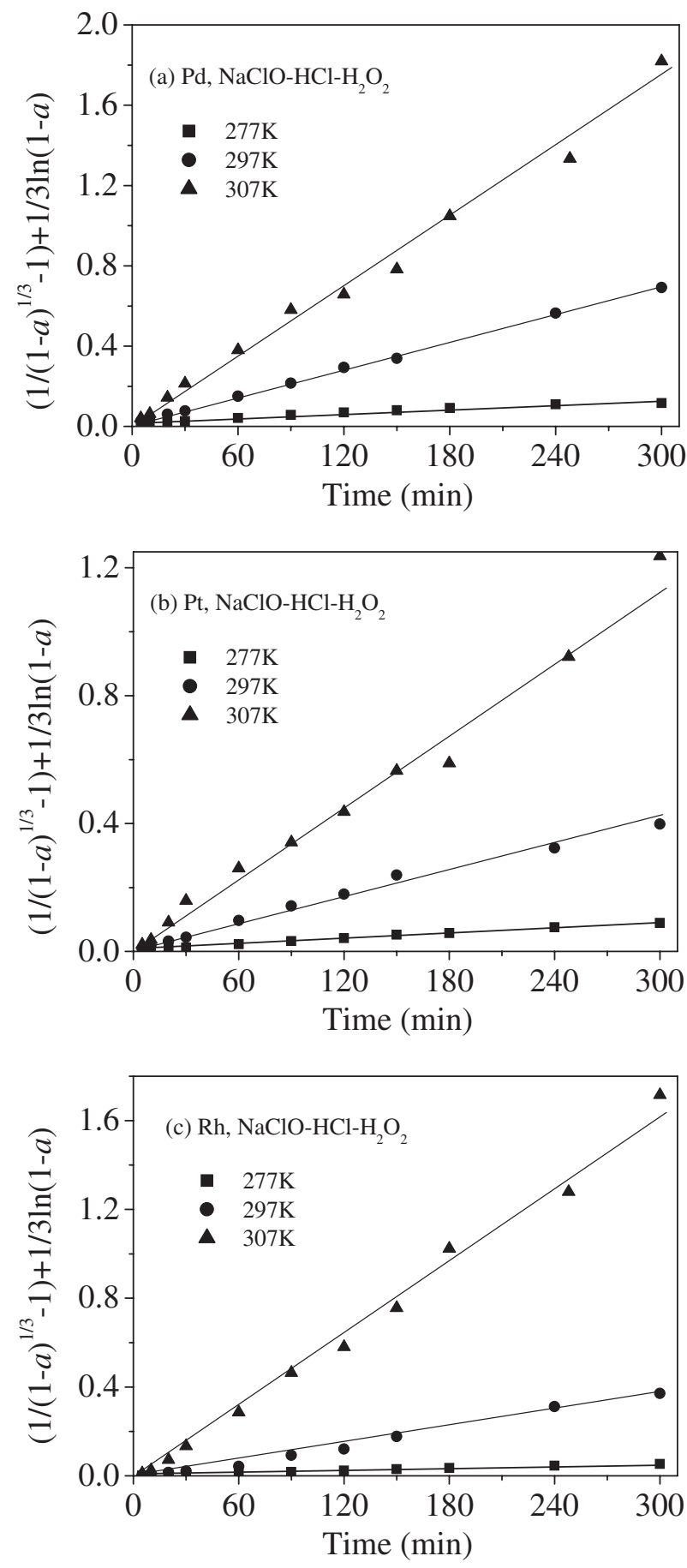

Fig. 8 Plot of kinetic equation parameter (D11, see Table 1) versus leaching time for the leaching of $\mathrm{Pd}$ (a), $\mathrm{Pt}$ (b) and $\mathrm{Rh}$ (c) in $\mathrm{NaClO}$ contained leaching solution: Effect of temperature.

necessary to fit the leaching kinetic data for the $\mathrm{HCl}-\mathrm{H}_{2} \mathrm{O}_{2}$ solution system. Further works are continuing to derivate new models by modifying assumptions according to the characteristics of the present system.

Figure 11 showed the Arrhenius plot for the leaching of Pt, $\mathrm{Pd}$ and $\mathrm{Rh}$, the data for the leaching of $\mathrm{Pt}$ and $\mathrm{Rh}$ in the $\mathrm{HCl}-$ $\mathrm{H}_{2} \mathrm{O}_{2}$ solution are not available. Indeed, good linear relations were exhibited as well. The activation energies were calculated as listed in Table 4. In the case of the $\mathrm{NaClO}$ contained solution (Fig. 11(a)), the activation energy for Pd, 

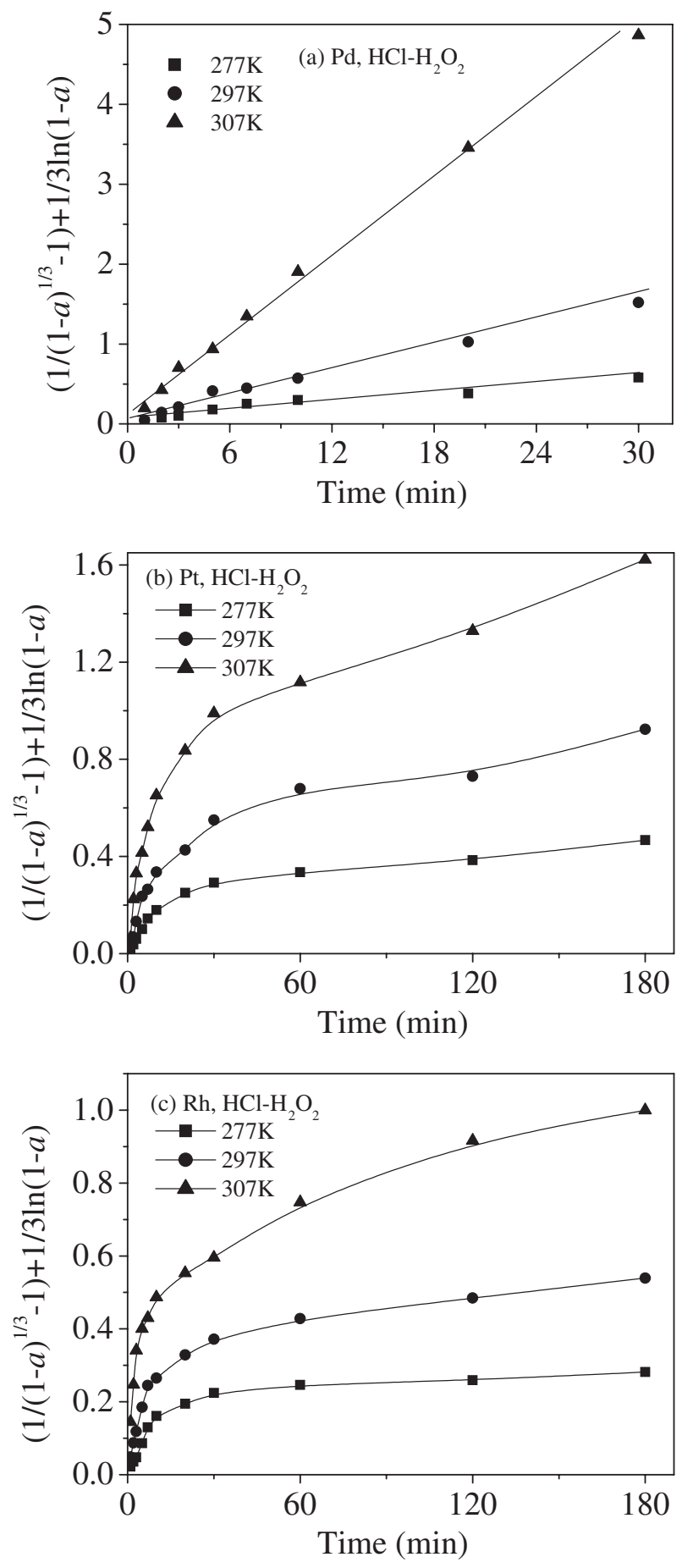

Fig. 9 Plot of kinetic equation parameter (D11, see Table 1) versus leaching time for the leaching of $\mathrm{Pd}(\mathrm{a}), \mathrm{Pt}(\mathrm{b})$ and $\mathrm{Rh}$ (c) in $\mathrm{HCl}-\mathrm{H}_{2} \mathrm{O}_{2}$ leaching solution: Effect of temperature.

Pt and Rh was 63.5, 59.1 and $77.9 \mathrm{~kJ} \mathrm{~mol}^{-1}$, respectively. It is interesting that activation energy is positively related to the formation potential of the chloro-complexes of the corresponding metals (see R1, R2 and R3 in the section of introduction). A correlation of 0.978 can be found, although one is the thermodynamic and the other is based on the reaction kinetics. Regarding to the leaching in the $\mathrm{HCl}-\mathrm{H}_{2} \mathrm{O}_{2}$ solution (Fig. 11(b)), the activation energy for $\mathrm{Pd}$ was $49.5 \mathrm{~kJ} \mathrm{~mol}^{-1}$ based on eq. D11, being lower than the corresponding value from the $\mathrm{NaClO}$ contained solution
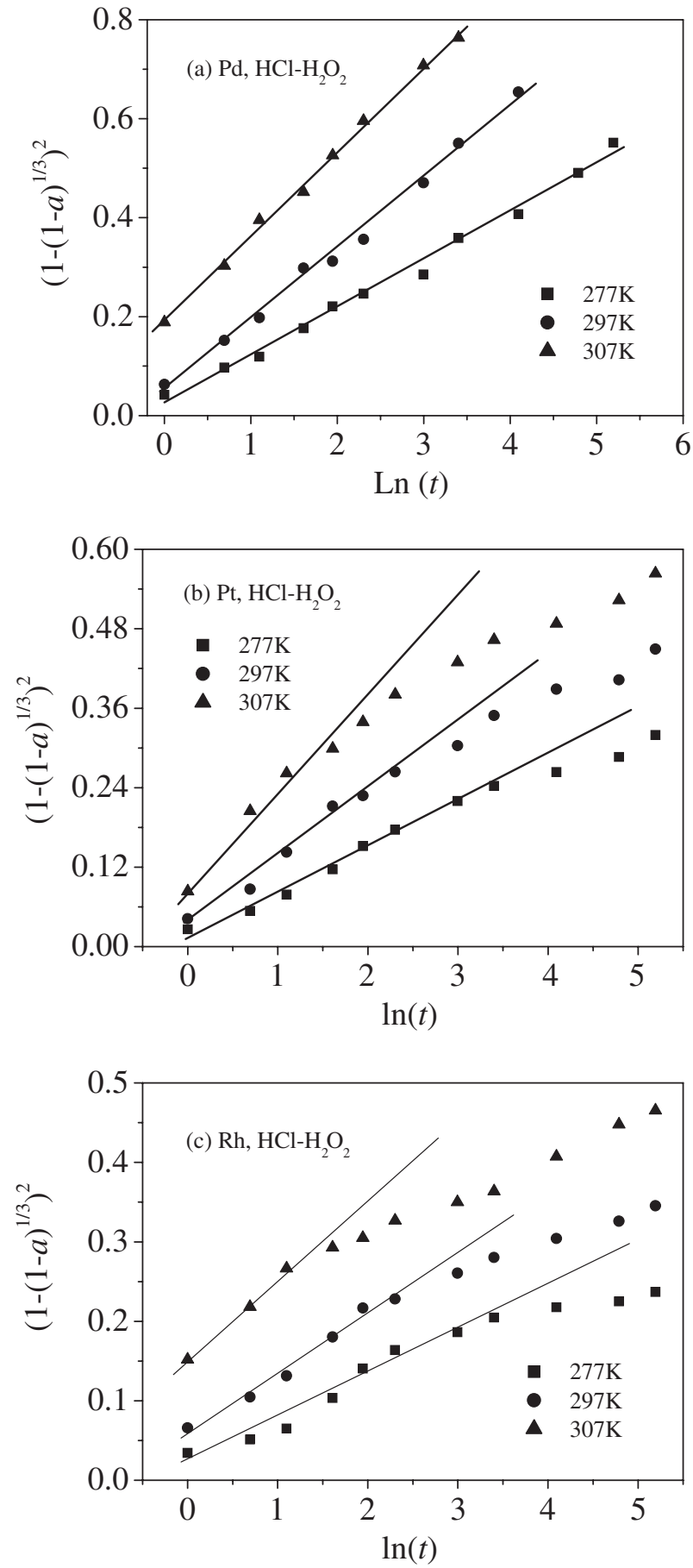

Fig. 10 Plot of $\left(1-(1-\alpha)^{1 / 3}\right)^{2}$ versus $\ln t$ for the leaching of $\mathrm{Pd}(\mathrm{a}), \mathrm{Pt}$ (b) and $\mathrm{Rh}(\mathrm{c})$ in $\mathrm{HCl}-\mathrm{H}_{2} \mathrm{O}_{2}$ leaching solution: Effect of temperature.

with $14 \mathrm{~kJ} \mathrm{~mol}^{-1}$. However, the activation energy for Pd was only $13.4 \mathrm{~kJ} \mathrm{~mol}^{-1}$ on the basis of eq. D7.

\subsection{Discussion}

The kinetic aspect in terms of the leaching of $\mathrm{Pt}, \mathrm{Pd}$ and $\mathrm{Rh}$ in the $\mathrm{NaClO}$ contained and $\mathrm{HCl}-\mathrm{H}_{2} \mathrm{O}_{2}$ leaching solutions has been analyzed and discussed based on the degree of correlations and best fitting to the zero intercept of each proposed models. The model D11 was found to be the most suitable to describe the leaching process of PGMs in the $\mathrm{NaClO}$ contained solution. According to the model deriva- 

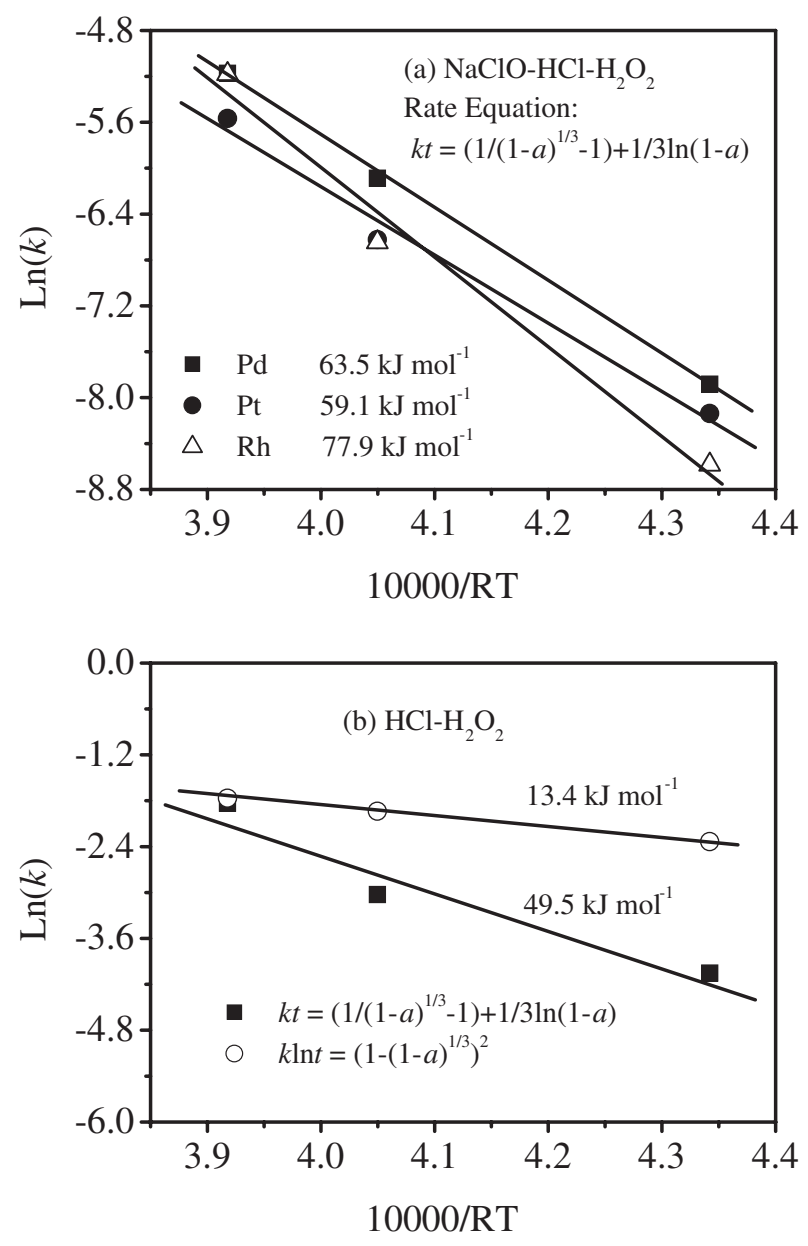

Fig. 11 Arrhenius plot for the leaching of PGMs: (a) $\mathrm{NaClO}-\mathrm{HCl}-\mathrm{H}_{2} \mathrm{O}_{2}$; (b) $\mathrm{HCl}-\mathrm{H}_{2} \mathrm{O}_{2}$.

tion of D11, it was shown that the interface transfer and diffusion across the leached support layer would both affect the rate of leaching reaction. In other words, a diffusioncontrolled mechanism will be dominant, although for the $\mathrm{Pt}$ and $\mathrm{Rh}$ leaching in the case of the $\mathrm{HCl}-\mathrm{H}_{2} \mathrm{O}_{2}$ solution, big deviations were found when using model D11 to fit the kinetic data. In this case, the support material will act as a product layer or ash layer (as called in some textbooks), ${ }^{10-12)}$ and was supposed to be stable during the reaction, and can remain constant particle size. In fact, in our experiment, more than 95 mass \% of the starting samples can be recovered as residues for the $\mathrm{NaClO}$ contained solution, although some other metals in the leaching solution can be detected by ICP, which might come from the doping layer of the support, showing that the reaction between the leaching solution and the support material was limited, and the support material is stable enough to form a leached support layer for the diffusion of leaching active components, and diffusion coefficient, $D_{\mathrm{e}}$, would basically be a constant if the structure of the catalyst was homogenous, which was a basic assumption during the model derivation of D11.

The interface transfer and diffusion-controlled mechanism seems can also be determined for those deviation situations particularly for $\mathrm{Pd}$, since the present $\mathrm{HCl}-\mathrm{H}_{2} \mathrm{O}_{2}$ solution is more active than the $\mathrm{NaClO}$ contained solution. That means the reaction rate of PGMs' dissolution in the $\mathrm{HCl}-\mathrm{H}_{2} \mathrm{O}_{2}$ solution will far faster than that in the $\mathrm{NaClO}$ contained solution intrinsically if the diffusion-controlled process did not exist in both cases, and since the diffusion-controlled mechanism is dominant in the case of $\mathrm{NaClO}$ contained solution, the same conclusion seems can be drawn for the $\mathrm{HCl}-\mathrm{H}_{2} \mathrm{O}_{2}$ solution. However, two additional aspects have to be considered. The first is that the diffusion of the main reactants e.g. $\mathrm{HCl}$ in the $\mathrm{HCl}-\mathrm{H}_{2} \mathrm{O}_{2}$ solution will be faster than that in the case of $\mathrm{NaClO}$ contained solution, because of the higher concentration of chloride ions. The fast diffusion of the reactant will promote the leaching of PGMs. The most important is that the increase of diffusion rate of the reactants will cause the kinetic mechanism of leaching prefer to the reaction control or a combination of both diffusion and reaction control. So, in this case the kinetic mechanism will depend on the intensity of the diffusion rate and intrinsic reaction rate. The second is that the $\mathrm{HCl}$ solution might react with the support materials more severely and might destroy the pore structure of the support materials to some extent, and make it easy to diffuse across the support layer for the leaching solution, corresponding to $D_{\mathrm{e}}$ of large value in effect. In fact, the leaching residue from the $\mathrm{NaClO}$ contained solution is slightly heavier than that from the $\mathrm{HCl}-\mathrm{H}_{2} \mathrm{O}_{2}$ solution, according to our experiment results (not shown here). The possibility of this kind of effect exists, although the leaching of Pd seems subject to the interface transfer and diffusion-controlled mechanism as suggested in the case of $\mathrm{NaClO}$ (Fig. 9(a)).

Further, the activation energy was also taken into account to analyze the reaction mechanism during the leaching of $\mathrm{Pt}$, $\mathrm{Pd}$ and $\mathrm{Rh}$. In general, the activation energy for a diffusioncontrolled process is characterized as being less than 21 $\mathrm{kJ} \mathrm{mol}^{-1}\left(=5 \mathrm{kcal} \mathrm{mol}^{-1}\right){ }^{12)}$ On the contrary, the activation energy of a reaction-controlled process is usually greater than $42 \mathrm{~kJ} \mathrm{~mol}^{-1}$ or more specifically in the range of $42-84$ $\mathrm{kJ} \mathrm{mol}^{-1}$. $^{12,13)}$ However, recent findings showed that the activation energies of some diffusion controlled reactions in the leaching processes of some metals can be more than $21 \mathrm{~kJ} \mathrm{~mol}^{-1}$, as listed in Table 5. ${ }^{14-19)}$ Although, there is no

Table 4 Activation energy of $\mathrm{Pt}$, Pd and $\mathrm{Rh}$ leaching in chloride solutions.

\begin{tabular}{|c|c|c|c|c|}
\hline \multirow{2}{*}{ Leaching solution } & \multirow{2}{*}{ Rate equations } & \multicolumn{3}{|c|}{ Activation energy $\left(\mathrm{kJ} \mathrm{mol}^{-1}\right)$} \\
\hline & & $\mathrm{Pd}$ & $\mathrm{Pt}$ & $\mathrm{Rh}$ \\
\hline $\mathrm{NaClO}-\mathrm{HCl}-\mathrm{H}_{2} \mathrm{O}_{2}$ & $k t=1 /(1-\alpha)^{1 / 3}+1 / 3 \ln (1-\alpha)-1$ & 63.5 & 59.1 & 77.9 \\
\hline $\mathrm{HCl}-\mathrm{H}_{2} \mathrm{O}_{2}$ & $k t=1 /(1-\alpha)^{1 / 3}+1 / 3 \ln (1-\alpha)-1$ & 49.5 & n.a. & n.a. \\
\hline $\mathrm{HCl}-\mathrm{H}_{2} \mathrm{O}_{2}$ & $k \ln t=\left(1-(1-\alpha)^{1 / 3}\right)^{2}$ & 13.4 & n.a. & n.a. \\
\hline
\end{tabular}


Table 5 Activation energy of some diffusion controlled reaction in the leaching processes.

\begin{tabular}{|c|c|c|c|c|}
\hline Authors & Metal extracted & $\begin{array}{l}\text { Leaching } \\
\text { solution }\end{array}$ & $\begin{array}{l}\text { Activation energy } \\
\left(\mathrm{kJ} \mathrm{mol}^{-1}\right)\end{array}$ & Ref. \\
\hline $\begin{array}{l}\text { P. K. Gbor, I. B. Ahmed and } \\
\text { C. Q. Jia }\end{array}$ & $\begin{array}{l}\mathrm{Ni}, \mathrm{Co} \text { and } \mathrm{Fe} \text { from } \\
\text { nickel smelter slag }\end{array}$ & $\mathrm{SO}_{2}(\mathrm{aq})$ & $\begin{array}{l}E_{a}(\mathrm{Co}, \mathrm{Fe})=70 \mathrm{~kJ} \mathrm{~mol}^{-1} \\
\mathrm{Ni}=50 \mathrm{~kJ} \mathrm{~mol}^{-1}\end{array}$ & 14) \\
\hline $\begin{array}{l}\text { H. Tsucida, E. Narita, } \\
\text { H. Takeuchi, M. Adachi } \\
\text { and T. Okabe }\end{array}$ & $\begin{array}{l}\mathrm{Ti} \text { and } \mathrm{Fe} \text { from } \\
\text { ilmenite ore }\end{array}$ & $\mathrm{HCl}(\mathrm{aq})$ & $\begin{array}{l}E_{a}(\mathrm{Ti})=48.9 \mathrm{~kJ} \mathrm{~mol}^{-1} \\
E_{a}(\mathrm{Fe})=53.7 \mathrm{~kJ} \mathrm{~mol}^{-1}\end{array}$ & 15) \\
\hline D. Georgiou & $\begin{array}{l}\text { Ni from limonitic } \\
\text { laterite }\end{array}$ & $\begin{array}{l}\text { Pressurized } \\
\mathrm{H}_{2} \mathrm{SO}_{4}\end{array}$ & $E_{a}(\mathrm{Ni})=49-79 \mathrm{~kJ} \mathrm{~mol}^{-1}$ & 17) \\
\hline $\begin{array}{l}\text { P. K. Jena, O. Barbosa-Filho } \\
\text { and I. C. Vasconcelos }\end{array}$ & $\begin{array}{l}\text { Zn from sphalerite } \\
\text { slurry }\end{array}$ & $\mathrm{Cl}_{2}(\mathrm{~g})$ & $E_{a}(\mathrm{Zn})=49.6 \mathrm{~kJ} \mathrm{~mol}^{-1}$ & 18) \\
\hline E. Olanipekun & $\begin{array}{l}\mathrm{Ti} \text { and } \mathrm{Fe} \text { from } \\
\text { Nigerian ilmenite ore }\end{array}$ & $\mathrm{HCl}(\mathrm{aq})$ & $\begin{array}{l}E_{a}(\mathrm{Ti})=67.1 \mathrm{~kJ} \mathrm{~mol}^{-1} \\
E_{a}(\mathrm{Fe})=62.4 \mathrm{~kJ} \mathrm{~mol}^{-1}\end{array}$ & 19) \\
\hline
\end{tabular}

satisfied explanation about those phenomena, they might be occur due to some special kinds of diffusion behaviors in the product layer, and higher activation energies were necessary.

As listed in Table 4, the activation energies for Pt, Pd and $\mathrm{Rh}$ leaching in the $\mathrm{NaClO}$ solution disagree with the category above, exhibiting a contradicting behavior. The possible reason is that the micro-porous structure of the catalyst in this case is quite different from the structure of product layer formed during the reaction, and the diffusion of $\mathrm{NaClO}$ contained leaching solution across the leached support layer of the catalyst residue might be very slow because of the micro-porous structure of the catalyst, higher activation energy was needed for the leaching reaction.

On the other hand, for the leaching in the $\mathrm{HCl}-\mathrm{H}_{2} \mathrm{O}_{2}$ solution, the activation energy for $\mathrm{Pd}$ was $49.5 \mathrm{~kJ} \mathrm{~mol}^{-1}$ based on eq. D11, being lower than the corresponding value from the $\mathrm{NaClO}$ contained solution with $14 \mathrm{~kJ} \mathrm{~mol}^{-1}$. At least, this can manifest to some extent that the diffusion of the $\mathrm{HCl}-\mathrm{H}_{2} \mathrm{O}_{2}$ solution is easier due to lower activation energy as compared with the corresponding value for the $\mathrm{NaClO}$ contained solution in spite of kinetic models. In fact, the activation energy was only $13.4 \mathrm{~kJ} \mathrm{~mol}^{-1}$ on the basis of model D7. According to the category, the kinetic model D7 works well for the leaching of $\mathrm{Pd}$ in the $\mathrm{HCl}-\mathrm{H}_{2} \mathrm{O}_{2}$ solution.

There is a question left to answer that why does the activation energy for the $\mathrm{HCl}-\mathrm{H}_{2} \mathrm{O}_{2}$ system quite differ from that for the $\mathrm{NaClO}$ system. We ascribe this to the reason that the $\mathrm{HCl}-\mathrm{H}_{2} \mathrm{O}_{2}$ solution was more active than the $\mathrm{NaClO}$ contained solution to wash the doping layer in the inner surface of the catalyst to expend micro-pores. This hypothesis is consistent with the kinetic data, which shows a rapid increase in the leaching rate for the $\mathrm{HCl}-\mathrm{H}_{2} \mathrm{O}_{2}$ solution.

Anyway, in the case of $\mathrm{Pd}$ leaching in the $\mathrm{HCl}-\mathrm{H}_{2} \mathrm{O}_{2}$ solution system, instead of interface transfer and diffusioncontrolled mechanism, the pure diffusion-controlled mechanism can be determined on the basis of model D7 according to the criterion of activation energy. In this model the diffusion constant was inversely proportional to the reaction time $t$. The reason for this phenomenon is still unclear, and for the leaching of $\mathrm{Pt}$ and $\mathrm{Rh}$, there must be some other unknown factors affecting the reactions, further works are in progress.

\section{Conclusion}

The kinetics on the leaching of $\mathrm{Pt}, \mathrm{Pd}$ and $\mathrm{Rh}$ from automotive catalyst residue in $\mathrm{NaClO}(3 \mathrm{vol} \%)-\mathrm{HCl}(5 \mathrm{M})-$ $\mathrm{H}_{2} \mathrm{O}_{2}(1 \mathrm{vol} \%)$ and $\mathrm{HCl}(11.6 \mathrm{M})-\mathrm{H}_{2} \mathrm{O}_{2}(1 \mathrm{vol} \%)$ solutions has been investigated. The results obtained in the present study are summarized as follows:

It is observed from the experiments and kinetic analysis that the kinetic model:

$$
\left((1-\alpha)^{-1 / 3}-1\right)+\frac{1}{3} \ln (1-\alpha)=k_{1} t
$$

was found to be the most suitable to describe the leaching process of PGMs in the $\mathrm{NaClO}$ contained solution. The interface transfer and diffusion across the leached support layer both affect the rate of leaching reaction.

$$
\text { Model (II): } \quad\left(1-(1-\alpha)^{1 / 3}\right)^{2}=k_{2} \ln (t)
$$

fits the kinetic data very well for the dissolution of $\mathrm{Pd}$ in the $\mathrm{HCl}-\mathrm{H}_{2} \mathrm{O}_{2}$ solution, showing that the diffusion across the leached support layer mainly affect the kinetic behaviors and the diffusion coefficient is inversely proportional to leaching time $t$.

For $\mathrm{Pt}$ and $\mathrm{Rh}$ leaching in the $\mathrm{HCl}-\mathrm{H}_{2} \mathrm{O}_{2}$ solution, apparent deviation was found when use this model to fit the kinetic data, thus, there must be some other unknown factors affecting the reaction.

The $\mathrm{NaClO}$ contained solution and $\mathrm{HCl}-\mathrm{H}_{2} \mathrm{O}_{2}$ solution leaching of $\mathrm{Pt}, \mathrm{Pd}$ and $\mathrm{Rh}$ are strongly dependent on the leaching temperature. In the case of the $\mathrm{NaClO}$ contained solution, the activation energy for $\mathrm{Pd}, \mathrm{Pt}$ and $\mathrm{Rh}$ was 63.5, 59.1 and $77.9 \mathrm{~kJ} \mathrm{~mol}^{-1}$, respectively. Due to the microporous structure of the catalyst, the diffusion of $\mathrm{NaClO}$ contained leaching solution across the leached support layer of the catalyst residue might be very slow, higher activation energy was needed for the leaching reaction. Regarding to the leaching in the $\mathrm{HCl}-\mathrm{H}_{2} \mathrm{O}_{2}$ solution, the activation energy for Pd was $13.4 \mathrm{~kJ} \mathrm{~mol}^{-1}$.

\section{REFERENCES}

1) K. Liu, W. T. Yen, A. Shibayama and T. Fujita: Hydrometallurgy 
2003-Proceeding of the 5th International Conference in Honor of Professor Ian Ritchie, vol. 2 (TMS, 2003) p. 1617-1628.

2) M. H. H. Mahmoud: J. of Material 3 (2003) 37-40.

3) L. Bolinski and P. A. Distin: Proceeding of International Conference on Extractive Metallurgy of Gold and Base Metals, (AusIMM, 1992) p. 277-280.

4) K.-Y. A. Wu, K. D. Wisecarver, M. A. Abraham, N. Takach and N. Yang: Proceeding of 17th International Precious Metals Conference, (International Precious Metals Institute, 1993) p. 343-349.

5) T. N. Angelidis: Topics in Catalysis 16/17 (2001) 419-423.

6) S. Harjanto, Y. Cao, A. Shibayama, I. Naitoh, T. Nanami, K. Kasahara, Y. Okumura, K. Liu and T. Fujita: Mater. Trans. 47 (2006) 129-135.

7) S. Gonomaru, H. Yamamoto and J. Shibata: Proceeding of MMIJ Meeting, (Summer, 2001) p. 73-74.

8) L. R. P. de Andrade Lima and D. Hodouin: Hydrometallurgy 79 (2005) 121-137.

9) C. F. Dickinson and G. R. Heal: Thermochimica Acta 340/341 (1999) 89-103.

10) O. Levenspiel: Chemical reaction engineering (Second edition), (John
Wiley \& Sons, Int., New York, 1972) p. 364-365.

11) M. E. Wadsworth and J. D. Miller: Hydrometallurgical processes. H. Y. Sohn, M. E. Wadsworth, (Eds.), Rate Processes of Extractive Metallurgy (Plenum Press, New York, 1979) pp. 133-199.

12) F. Habashi: Principles of Extractive Metallurgy, (Gordon and Breach Science Publ., New York, 1969) p. 140-164.

13) S. Anand and R. P. Das: Trans. Indian Inst. Met. 41 (1988) 335-341.

14) P. K. Gbor, I. B. Ahmed and C. Q. Jia: Hydrometallurgy 57 (2000) 1322.

15) H. Tsucida, E. Narita, H. Takeuchi, M. Adachi and T. Okabe: Bull. Chem. Soc. Jpn. 55/6 (1982) 1934-1938.

16) Y. Paspaliaris and Y. Tsolakis: Hydrometallurgy 19 (1987) 259-266.

17) D. Georgiou: Kinetic of nickel dissolution during sulphuric acid pressure leaching of a limonitic laterite. MASc. Thesis. University of Toronto, Canada (1995) p. 85-89.

18) P. K. Jena, O. Barbosa-Filho and I. C. Vasconcelos: Hydrometallurgy 52 (1999) 111-122.

19) E. Olanipekun: Hydrometallurgy 53 (1999) 1-10. 